\title{
Analysis and Application of the Examination Results of Nursing Major in Yunnan Province in the Past Three Years-Taking the Upgrading Exam from Junior College to University as an Example
}

\author{
Xisong Miao ${ }^{1, *}$, Ruining Zhang ${ }^{2}$, Boyang Wang ${ }^{1}$, Zhangliao $\mathrm{Xu}^{1,3}$, Hangwei Zhang ${ }^{1}$ and \\ Zirui $\mathrm{Li}^{1}$ \\ ${ }^{1}$ School of Information Engineering, Kunming University, 650214 Kunming, China \\ ${ }^{2}$ School of Medicine, Kunming University, 650214 Kunming, China \\ ${ }^{3}$ The Key Laboratory of College Data Governance and Intelligent Decision-making of Yunnan Province, 650214 \\ Kunming, China \\ *Corresponding author.Email:48416017@qq.com
}

\begin{abstract}
This work analyzed the results of the Upgrading Exam from Junior College to University (UEJCU) in the recent three years in Yunnan, found out the deficiencies and reasons of the skills test candidates, and provided relevant basis and reference for the departments of relevant medical colleges and education. This study used SPSS 25.0 to analyze the three-year nursing professional skills examination, compare the overall scores of the three years, and compare the scores of private and public schools respectively. The results have statistical significance. With the rise of the examinee increased significantly year by year, the total average result of the three years of shows a declining trend according to the analysis of the results. The number of participants in public schools is greater than that of private schools, and the total score is higher than that of private schools, which fully explains the importance and necessity of strengthening the practical operation of medical colleges.
\end{abstract}

Keywords: Nursing, Upgrading Exam from Junior College to University, Skill test, Achievement analysis

\section{INTRODUCTION}

From the perspective of the requirements for the medical field since the 13th Five-Year Plan, coupled with China's development status towards an aging society and the opening of the two-child policy and the outbreak of COVID-19 in 2020, there is a big gap in China's medical professionals, and the country has an urgent demand for medical talents. In order to practice the national "strengthening the health personnel team construction strategy", coupled with the increase of students' job-hunting pressure, more and more students choose to take the fulltime exam to study again. In order to promote the scientific selection of talents and the continuous export of highquality nursing personnel for the country, we should strengthen the assessment of clinical practice ability with solid theoretical foundation under the increasingly serious relationship between care and patients. In recent years, skills tests are particularly important. In order to fully grasp the level of the nursing major UEJCU examination in the past three years, we have made a comprehensive and systematic analysis of the skills test results of 5,657 students who took the nursing major UEJCU test in Yunnan Province in the three years from 2017 to 2019 . The aim is to understand the current situation of UEJCU " practical skills examination in Yunnan Province, analyze the existing problems in the practice teaching of medical and health higher vocational education in various places, and put forward reform suggestions.

\section{DATA AND METHODS}

\subsection{Exam Subject}

From 2017 to 2019, we used the candidate participated in the medical and health care UEJCU nursing major in Yunnan Province, covering the fresh graduates of higher vocational schools and vocational and technical schools in the whole province. The total number of examinees accounted for 5,657 students, including 3,085 in public schools and 2,573 in private schools, 528 in $2017,1,726$ in 2018 , and 3,403 in 2019. It involved 24 schools, 11 public schools and 13 private schools. 


\subsection{Exam Content}

The test is nursing major skills, including intravenous infusion, cardiopulmonary resuscitation, vital signs measurement.

\subsection{Methods}

Data analysis was performed using the SPSS 25.0 software. Measurement data are indicated using $( \pm \mathrm{s})$, and independent sample t-test is used between public and private groups. Three-year comparisons were performed by one-way ANOVA and pairwise post-hoc comparisons by the LSD test [1-2]. The inspection level $(\alpha)$ is 0.05 .

\section{RESULTS AND ANALYSIS}

\subsection{Distribution of Exam Scores}

A comprehensive and objective understanding of the total scores of candidates and various scores from 2017 to 2019 will provide the corresponding basis for the data analysis of independent sample t-test, one-way ANOVA and LSD test when using SPSS statistical software. The distribution of the total score of the nursing UEJCU exam in the past three years are shown in Table 1.

Table 1. Comparison of the overall three-year skill test scores

\begin{tabular}{|c|c|c|c|c|c|}
\hline Groups & Cases & $\begin{array}{c}\text { Venous } \\
\text { transfusion }\end{array}$ & $\begin{array}{c}\text { Cardio-pulmonary } \\
\text { resuscitation }\end{array}$ & $\begin{array}{c}\text { Measurements of vital } \\
\text { signs }\end{array}$ & Total points \\
\hline 2017 & 528 & $40.67 \pm 4.66$ & $36.31 \pm 7.12$ & $39.07 \pm 5.95$ & $116.05 \pm 13.33$ \\
\hline 2018 & 1726 & $37.68 \pm 6.28^{*}$ & $36.90 \pm 6.18$ & $38.10 \pm 6.46^{*}$ & $112.73 \pm 13.67^{*}$ \\
\hline 2019 & 3403 & $36.07 \pm 6.58^{* \#}$ & $37.19 \pm 6.06^{*}$ & $37.33 \pm 5.77^{* \#}$ & $110.59 \pm 13.62^{* \#}$ \\
\hline & $\mathrm{F}$ & 129.526 & 4.851 & 22.633 & 40.838 \\
\hline & $\mathrm{P}$ & $<0.001$ & 0.008 & $<0.001$ & $<0.001$ \\
\hline
\end{tabular}

Note: * indicates the comparison to $2017, \mathrm{P}<0.05$; \# indicates the comparison to $2018, \mathrm{P}<0.05$

Overall three-year score comparison, the venous transfusion, cardio-pulmonary resuscitation, measurements of vital signs and the total results were statistically significant $(\mathrm{P}<0.05)$. Pairwise post comparison afterwards: the venous transfusion, measurements of vital signs, and the total results in 2017 were greater than those in 2018, 2019. The cardio-pulmonary resuscitation was greater in 2019 than in 2017.

\subsection{Comparison of the Nursing Major UEJCU Exam Scores of Public Schools and Private Schools}

In comparing the scores in private universities in three years, the differences between venous transfusion and cardio-pulmonary resuscitation are statistically significant $(\mathrm{P}<0.05)$. The venous transfusion in 2017 is greater than that in 2018,2019 , and the cardio-pulmonary resuscitation in 2017 is less than that in 2018,2 019. The differences between measurements of vital signs and total points have not statistically significant $(\mathrm{P}>0.05)$. In comparing the scores in public universities in three years, the differences among venous transfusion, measurements of vital signs and total points are statistically significant $(\mathrm{P}<0.05)$. The 2017 total points of venous transfusion and measurements of vital signs are larger than that of 2018 and 2019. The cardiopulmonary resuscitation difference was not statistically significant $(\mathrm{P}>0.05)$, as shown in Table 2 .

Overall comparison of private and public scores: the differences were statistically significant $(\mathrm{P}<0.05)$ in venous transfusion, cardio-pulmonary resuscitation, measurements of vital signs, and total points, implying that the scores of the venous transfusion, cardio-pulmonary resuscitation, measurements of vital signs, total points in the public colleges were higher than that of private colleges, as shown in Table 3.

Comparison of private and public scores in 2017: the differences were statistically significant $(\mathrm{P}<0.05)$ in venous transfusion, cardio-pulmonary resuscitation, measurements of vital signs, and total points, implying that the scores of the venous transfusion, cardio-pulmonary resuscitation, measurements of vital signs, total points in the public colleges were higher than that of private colleges. Comparison of private and public scores in 2018: the differences were statistically significant $(\mathrm{P}<0.05)$ in venous transfusion, cardio-pulmonary resuscitation, measurements of vital signs, and total points, implying that the scores of the venous transfusion, cardio-pulmonary resuscitation, measurements of vital signs, and total points in the public colleges were higher than that of private colleges. Comparison of private and public scores in 2019: the differences were statistically significant $(\mathrm{P}<0.05)$ in cardiopulmonary resuscitation, implying that the scores of the cardio-pulmonary resuscitation in the public colleges were higher than that of private colleges. The differences among venous transfusion, measurements of vital signs, and total points were not statistically significant $(\mathrm{P}>0.05)$, implying there were no significant differences among the scores of transfusions, measurements of vital signs, and total points, as shown in Table 4. 
Table 2. Comparison of various skill scores in public and private colleges in the past three years

\begin{tabular}{|c|c|c|c|c|c|c|}
\hline $\begin{array}{c}\text { School } \\
\text { category }\end{array}$ & Goups & Cases & $\begin{array}{c}\text { Venous } \\
\text { transfusion }\end{array}$ & $\begin{array}{c}\text { Cardio-pulmonary } \\
\text { resuscitation }\end{array}$ & $\begin{array}{c}\text { Measurements of } \\
\text { vital signs }\end{array}$ & Total points \\
\hline \multirow{4}{*}{ Public } & 2017 & 221 & $39.92 \pm 5.06$ & $33.7 \pm 7.99$ & $37.79 \pm 6.31$ & $111.49 \pm 14.52$ \\
\cline { 2 - 7 } & 2018 & 755 & $36.6 \pm 6.64^{*}$ & $36.0 \pm 6.48^{*}$ & $37.58 \pm 6.55$ & $110.37 \pm 14.4$ \\
\cline { 2 - 7 } & 2019 & 1596 & $36.1 \pm 6.76^{*}$ & $36.6 \pm 5.99^{*}$ & $37.27 \pm 5.68$ & $110.1 \pm 13.8$ \\
\cline { 2 - 7 } & & $\mathrm{F}$ & 30.736 & 19.907 & 1.107 & 0.934 \\
\cline { 2 - 7 } & 2017 & $\mathrm{P}$ & $<0.001$ & $<0.001$ & 39.331 & 0.393 \\
\cline { 2 - 7 } & 2018 & 971 & $38.52 \pm 5.85^{*}$ & $37.60 \pm 5.84$ & $38.52 \pm 6.36^{*}$ & $114.7 \pm 12.70^{*}$ \\
\cline { 2 - 7 } & 2019 & 1807 & $35.97 \pm 6.42^{* \#}$ & $37.66 \pm 6.09$ & $37.38 \pm 5.85^{* \#}$ & $111.0 \pm 13.45^{* \#}$ \\
\cline { 2 - 7 } & & $\mathrm{F}$ & 117.61 & 0.853 & 28.62 & 60.878 \\
\cline { 2 - 7 } & & $\mathrm{P}$ & $<0.001$ & 0.426 & $<0.001$ & $<0.001$ \\
\hline
\end{tabular}

Table 3. Comparison of the scores of the overall private and public skill tests

\begin{tabular}{|c|c|c|c|c|c|}
\hline Goups & Cases & $\begin{array}{c}\text { Venous } \\
\text { transfusion }\end{array}$ & $\begin{array}{c}\text { Cardio-pulmonary } \\
\text { resuscitation }\end{array}$ & $\begin{array}{c}\text { Measurements of vital } \\
\text { signs }\end{array}$ & Total points \\
\hline Public & 2572 & $36.66 \pm 6.67$ & $36.23 \pm 6.39$ & $37.4 \pm 5.99$ & $110.31 \pm 14.03$ \\
\hline Private & 3085 & $37.29 \pm 6.31$ & $37.7 \pm 5.99$ & $38 \pm 6.02$ & $113 \pm 13.3$ \\
\hline & $\mathrm{t}$ & -3.368 & -8.299 & -3.468 & -6.907 \\
\hline & $\mathrm{P}$ & 0.001 & $<0.001$ & 0.001 & $<0.001$ \\
\hline
\end{tabular}

Table 4. Comparison of scores of private and public skills examinations in 2017-2019

\begin{tabular}{|c|c|c|c|c|c|c|}
\hline Years & Groups & Cases & Venous transfusion & $\begin{array}{l}\text { Cardio-pulmonary } \\
\text { resuscitation }\end{array}$ & $\begin{array}{l}\text { Measurements of } \\
\text { vital signs }\end{array}$ & Total points \\
\hline \multirow{4}{*}{2017} & Public & 221 & $39.92 \pm 5.06$ & $33.78 \pm 7.99$ & $37.79 \pm 6.31$ & $111.49 \pm 14.52$ \\
\hline & Private & 307 & $41.21 \pm 4.28$ & $38.11 \pm 5.8$ & $39.99 \pm 5.5$ & $119.31 \pm 11.35$ \\
\hline & & $\mathrm{t}$ & -3.069 & -6.824 & -4.226 & -6.632 \\
\hline & & $\mathrm{P}$ & 0.002 & $<0.001$ & $<0.001$ & $<0.001$ \\
\hline \multirow{4}{*}{2018} & Public & 755 & $36.68 \pm 6.64$ & $36.07 \pm 6.48$ & $37.58 \pm 6.55$ & $110.37 \pm 14.4$ \\
\hline & Private & 971 & $38.52 \pm 5.85$ & $37.6 \pm 5.84$ & $38.52 \pm 6.36$ & $114.7 \pm 12.7$ \\
\hline & & $\mathrm{t}$ & -5.415 & -4.606 & -2.698 & -5.872 \\
\hline & & $\mathrm{P}$ & $<0.001$ & $<0.001$ & 0.007 & $<0.001$ \\
\hline \multirow{4}{*}{2019} & Public & 1596 & $36.17 \pm 6.76$ & $36.67 \pm 5.99$ & $37.27 \pm 5.68$ & $110.1 \pm 13.8$ \\
\hline & Private & 1807 & $35.97 \pm 6.42$ & $37.66 \pm 6.09$ & $37.38 \pm 5.85$ & $111.02 \pm 13.45$ \\
\hline & & $\mathrm{t}$ & 0.810 & -4.547 & -0.525 & -1.863 \\
\hline & & $\mathrm{P}$ & 0.418 & $<0.001$ & 0.600 & 0.063 \\
\hline
\end{tabular}

\subsection{Analysis of the Overall Situation of the Nursing Major UEJCU Examination Results}

The distribution of overall nursing major UEJCU examination results in Yunnan province from 2017 to 2019 showed that total points decreased year by year. In the three skills operations, the performance increased year by year. However, the candidates have a good grasp of the cardiopulmonary resuscitation technology, and the venous transfusion and measurements of vital signs practices are relatively poor (see Table 1). The better results in the cardiopulmonary resuscitation skills test may be related to the increased national awareness of first aid and the cardiopulmonary resuscitation is a very important first aid operation skill outside the hospital. It has a high penetration rate among the people, and the training is not limited by time, occasion and tools, and more pre-test training. However, the reason for losing points in the venous transfusion and measurements of vital signs skills tests is related to the cumbersome test procedures and force majeure factors such as training sites, models and tools. There are some higher vocational school teaching resources and experimental teaching conditions closely related to this matter.

\subsection{Analysis of the Reasons for Missing Points in the Skill Operation Examination}

Based on the individual operation performance and total points over the years, the reasons for losing points in the 
skill operation examination are: (1) the theoretical knowledge of practical operation is not skilled; (2) poor ability to combine theoretical knowledge and practical operation; (3) unfamiliar with the operation steps of the skill test; (4) the test environment has changed for some candidates; (5) some candidates have a poor examination of psychological quality; (6) candidates' improper placement and handling of the examination materials; (7) candidates have an improper grasp of the examination time; (8) lack of due humanistic care; (9) careless and no attention to details during the examination; (10) some candidates have less training time before the test; (11) candidates are not familiar with the exam outline before the exam [4].

\subsection{Comparison and Reason Analysis of Candidates in Public and Private Schools}

According to the analysis of the results of public and private schools, the vast majority of students in public schools are better than those in private schools, and in 2019, private schools are better than public schools in venous transfusion, as shown in Table 2 and Table 3. Compared with public schools, private schools have a relatively short running time, a shallow historical foundation, and no accumulation of high-quality talents [4], so the Experimental teaching conditions are limited, resulting in insufficient laboratory construction. Due to the lack of practical teaching links, students' level of practice is uneven. Public schools have a long history and are relatively perfect in terms of teachers, experimental conditions, teaching facilities and teaching plans. Therefore, the difference between the examinee scores of public schools and private schools has a lot to do with the above reasons [5].

\section{SUGGESTIONS AND MEASURES}

From 2017 to 2019, the number of nursing major UEJCU examination participants increased year by year and reached a large extent, but the results of practical operation decreased year by year, and the results of public schools was higher than that of those of private schools. Therefore, relevant suggestions are put forward for the schools and educational institutions for reference: (1) Schools should strengthen the theoretical learning in the skill operation teaching, and strengthen the combination of theory and practical operation; (2) The practical operation ability should be strengthened to use and master this skill; (3) Schools should strengthen the training of students' psychological quality, and can take various modes, such as strengthening skills assessment, holding relevant skills competitions, and conducting pre-test training, to exercise students' psychological quality. Each school should teach students according to their talents and make targeted teaching. Each school in the usual teaching to strictly require candidates in accordance with the test skills operation steps, do the usual and the same test, so as to reduce the psychological pressure of the test; (4) Schools should strengthen the teachers, enhance the teaching level, comprehensively optimize the educational environment, improve the traditional teaching mode, and carry out the "flipped classroom" mode of teaching, reflecting the teaching concept of teachers as the leading role and students as the main body [6]. Teaching resources are put into balanced use to bring PBL teaching mode to the usual training and learning, and to make reasonable application. (5) Teaching and practice hospitals should pay close attention to the operation. The usual nursing skills operation should be standardized and complete, and the assessment of the skill operation should be strictly required when replacing the learning department. Teachers should be required to urge and guide nursing students, but also to improve their own nursing skills operation ability, teaching norms and complete, to protect a student to do a good example; (6) In the school or internship, teachers or clinical teaching teachers should strengthen the examinee's training of clinical thinking, so that in the operation of the exam will be more calm even in case of the exam emergency; (7) Candidates loss more points in the humanistic link of medical care in the examination, and so it should pay attention to the humanistic care in the school and clinical practice training, reflecting the concept of "modern medical mode" [6-8]; (8) In the process of internship, nursing students should also strengthen the training of basic nursing skills operation, and modestly consult the teaching persons, rather than passively waiting to the answers [9].

\section{CONCLUSIONS}

(1) The values of the venous transfusion, measurements of vital signs, and total points in 2017 is higher than that in 2018 and 2019. The cardio-pulmonary resuscitation in 2019 is greater than that in 2017 .

(2) The difference between the scores of public schools and the scores of private schools is greatly related to the length of running time, the historical foundation, the accumulation of high-quality talents, the experimental teaching conditions, the laboratory construction, the practical teaching links, and the students' practical operation level.

(3) Students should pay close attention to the operation. The usual nursing skills operation should be standardized and complete, and the skills operation assessment should be strictly required.

(4) The examination and clinical practice training should be focused on strengthening and cultivating students' humanistic care.

\section{REFERENCES}

[1] Miao Xisong, Yu Shan, Wang Anqi, Wang Yang, Xiang Wenjuan. The Performance Analysis of the First Medical and Health "College Entrance Vocational Skills Test" for Three Kinds of Vocational School Students in Yunnan Province [J]. Journal of Kunming Medical University, 2016, 37(04): 141-144. 
[2] Miao Xisong, Yu Shan, Wang Anqi, Wang Yang, Chen Tong, Lu Siyu, Zhao Yating. The Performance Assessment and Application of Two Sessions Medical and Health Category " Skill Entrance" in Yunnan Province [J]. Journal of Kunming Medical University, 2017, 38(02): 131-135.

[3] Yang Xuxia, Wang Jingna, Jiang Hong. Intentions to participate in the graduate entrance examination among RN-to-Baccalaureate nursing students [J]. Chinese Journal of Nursing Education, 2014, 11(10): 743-746.

[4] Liu Yulian, Xiao Changjiao. Analysis of nursing operation examination scores and related factors[J]. China Medical Herald, 2009, 6(04): 101-102.

[5] An Ying, Chen Xue, Xu Bo. Comparison and analysis of medical function assessment results to the Clinical medicine and nursing top-up program in Jilin medical university [J]. Chinese Journal of
Ethnomedicine and Ethnopharmacy, 2015, 24(23): 163$164+166$.

[6] Zhao Haiping, Yang Yu. Comparative analysis of learning styles and differences in academic performance of nursing students from special school to college in Chinese medical university [J]. Nursing Research, 2009, 23(26): 2370-2373.

[7] Ma Ting. Analysis of the influencing factors of basic nursing skills before graduation $[\mathrm{J}]$. Health Vocational Education, 2020, 38(10): 125-126.

[8] Mog Jianwei. Problems and Countermeasures for the Construction of teachers in Private Schools [J]. Pearl River Education Forum, 2020 (01): 47-49.

[9] Wang Yunxia, Jin Ruihua, Li Xiaokun. Determinants of basic nursing skill examination results for baccalaureate nursing students after internship [J]. Journal of Nursing Science, 2017, 32(05): 72-76. 